I may further add that the formula for band spectrum,

$$
n^{\prime}=\omega^{\prime}+a^{\prime} m^{\prime 2}+b^{\prime} m^{\prime 3}+c^{\prime} m^{\prime 4}+d^{\prime} m^{\prime a}+\ldots
$$

which I have deduced as an extension of Deslandre's formula, is one of the empirical formulæ used by Kayser and Runge for cyanogen bands (Abhandl. d. Berlin. Akad. d. Wissensch., 1889 , formula $I_{a}$ ). From $m^{\prime}=0$ to $m^{\prime}=150$, the difference in wave-lengths between calculation and observation seldom exceeds $\pm 0.03 \times 10^{-10} \mathrm{~m}$., which is quite within errors of observation.

H. NAGAOKA.

Physical Laboratory, Tokyo University, April 20.

\section{Electromotive Force between Two Phases of the same Metal.}

1 was much interested in the letter of $\mathrm{Mr}$. George Beilby in your issue of May 12. It may interest Mr. Beilby to know that I contributed a paper to the Institution of Civil Engineers on "The Effect of Stress on the Corrosion of Metals" (Proc. Inst. C.E., vol. cxviii., session 1893-4). On perusing this paper it will be seen that the results were somewhat analogous to the line of investigation $\mathrm{Mr}$. Beilby is undertaking. The experiments were on an extensive scale, and were made on numerous samples of iron and steel. In each case a polished bar of the steel or other metal, of known chemical composition and physical properties, used was cut in two; one half was stressed, and the other remained in its normal state. Each pair of bars was immersed in sea water, as an electrolyte, forming the elements of a galvanic couple, with a delicate calibrated galvanometer in circuit, when a decidedly measurable E.M.F. was observed. It was invariably noticed that the alteration in the physical properties of the metals produced by the stress only in each stressed bar was sufficient to place that bar in the position of copper in a zinc copper cell, the normal unstressed bar answering to the zinc element in a galvanic couple.

A current is also set up between two polished bars of the same metal immersed in a suitable electrolyte, one being in its normal state and the other having had its microcrystalline structure altered by annealing, in the manner illustrated in a recent paper to the Institution of Civil Engineers ("Effects of Annealing on Steel Rails," by Thomas Andrews and Charles Reginald Andrews, Proc. Inst. C.E., vol. clvi., session 1903-4, part ii.). When a metal is stressed a similar effect is produced. I have for some time past been working on a research on the E.M.F. between normal and annealed metals, using in one part of the investigation a complete series of specially prepared pure iron and steel bars of varied and known chemical composition, the object of the investigation being to show the E.M.F. produced between annealed and unannealed metals. I am much pleased to learn that Mr. Beilby is also working on this very interesting subject.

Mr. Beilby may also be interested in a research which I made some years ago showing the E.M.F. produced between polished bars of platinum or other metals, cut from the same bar, the E.M.F. being attributable to difference of molecular structure induced by heating one of the bars. The electrolytes employed for these experiments were fused salts at a high temperature (see "Electrochemical Reactions between Metals in Fused Salts," by Thomas Andrews, Trans. Royal Society, Edinburgh, session I885-6). I venture to suggest that the following papers (" Observations on Variations of the Electromotive Force between Metals at High Temperatures in Fused Salts," Trans. Royal Society, London, I 885 ; " Electrochemical Effects on Magnetising Iron," parts i., ii., iii., iv., Trans. Royal Society, L.ondon, $1887,1888,1889$, I 892 ), which I published some time ago, may perhaps be helpful to $\mathrm{Mr}$. Beilby in the course of his researches, the results of which $I$ am looking forward to with much interest and pleasure.

Wortley, near Sheffield, June 3

\section{Graphic Methods in an Educational Course in} Mechanics.

IN company, I think, with other correspondents, I have misunderstood Mr. Larden's use of the words " analytical methods." He alluded, it is true, to resolution and taking moments, but " analytical methods," especially when used in contradistinction to " graphical," have a much wider and more commonly received meaning. Dr. Murray's dictionary defines modern mathematical analysis as "the resolving of problems by reducing them to equations," and cites Hutton, "Course Math.," 1827 , "Analysis or Analytical method is that which is commonly used in Algebra." Prof. Croom Robertson, in "Analysis" in the "Ency: Brit.," says :- "In modern times analysis has come to mean the employment of the algebraical and higher calculus, and synthesis any direct treatment of the properties of geometrical figures, in the manner of the ancients without the use of algebraical notation or transformations." "Analytical" is a hard-worked word, like potential and polarisation, and no doubt it may be used in Mr. Larden's sense. The word " analytical," in the sense of the employment of algebra and the higher calculus, is not self-explanatory, and "graphical" or "geometrical" are better for this reason than "synthetical," unless the philosophical aspect is under discussion.

There can be no question that for almost all mathematical calculation and research, algebraical methods are far more powerful than geometrical (but I make reserv. ations), and teachers are perhaps for this reason apt to think that they are more useful and better suited for educational explanations of phenomena or of natural laws. If in mistaking $\mathrm{Mr}$. Larden for an unusually pronounced teacher of this type I have protested too strongly, I apologise, but his parenthetical queries which I have provoked I deny.

That some persons have accurate musical "ears," and others " no ear for music," that some can draw excellently without having been taught, and others can never learn, may perhaps be explained by physiological psychology. Some are "good at languages," and others bad; some have a "good head for figures," and others not. Experts in pedagogy might be able to tell us whether this is due to some selective ability or inability. But that some persons use algebra and the calculus with facility, and are bored by geometry, while others have "no head for algebra," but have an aptitude for geometrical methods, seems to be a matter worthy of investigation by the mental philosopher.

Not only has Mr. Larden used " analytical" in a somewhat restricted sense, but in this discussion he limits " graphic methods" to " those methods that depend on accurate drawing only, there being no calculation. ...." I will give one example of what I mean by a graphical method in an educational course. The fundamental idea of a differential coefficient is explained in the old text-books purely by symbols. Persons with " no head for algebra" find the greatest difficulty in grasping the idea. But draw a curve of speeds on the black-board, and explain that a tangent to it, or the slope at any point, gives the acceleration or rate of increase. You need no accurate drawing, no calculation, no algebra, but you give a perfectly clear idea of a differential coefficient.

It is rather hard that those who are called calculus dodgers cannot discuss the relative advantages of algebraical and geometrical methods without being accused of writing against mathematics or deprecatingly of mathematicians.

Westminster, June 6.

A. P. Trotter.

\section{Association of Economic Biologists.}

For some time past workers engaged upon various problems connected with economic biology have felt the need of some organisation whereby they could meet from time to time to discuss these different problems with fellowworkers so as to bring out suggestions and to prevent unnecessary duplication of work, and generally to promote and advance the economic side of biological science.

With a view to the formation of such an association of economic biologists, I have briefly discussed the matter with a few fellow-workers, and I shall be pleased to receive an expression of opinion or suggestions from any others.

The idea at present in my mind is an association somewhat on the lines of the American one; which would include and welcome all investigators and teachers in economic biology in its widest sense.

Mr. Fred. V. Theobald (Wye) writes :- "Your suggestion for an Association of Economic Biologists is most excellent.

NO. I806, VOL 70] 